\title{
A CRIAÇÃO DE MUNICÍPIOS: UMA AÇÃO TRANSESCALAR RESULTADO DA RELAÇÃO SOCIEDADE E ESPAÇO.
}

\author{
Adilar Antonio Cigolini ${ }^{1}$
}

\section{Resumo}

Nas últimas duas décadas do século $\mathrm{XX}$, o território brasileiro passou por uma intensa compartimentação do seu território, processo agregou mais de 1.500 novos municípios a sua malha municipal. Essa reconfiguração da divisão do território, em escala local, foi tema de pesquisa de inumeras áreas científicas, como geografia, ciências sociais, econômicas e jurídicas. O presente artigo faz uma análise dessas pesquisas, procurando desvendar o conteúdo explicativo para o fenômeno, fornecido pelos diferentes pesquisadores, bem como aponta avanços e limitações dessas explicações. Com base nesses avanços e limitações, procura construir uma explicação de cunho geográfico, qualficando o fenômeno como uma ação transescalar, resultado da relação do homem com o espaço geográfico.

Palavras chave: criação de município, emancipação municipal, escala geográfica, divisão territorial.

\section{CREATION OF MUNICIPALITIES: A TRANSCALAR ACTION RESULTING FROM THE SOCIETY AND SPACE RELATIONSHIP.}

\begin{abstract}
In the last two decades of the twentieth century, the Brazilian territory was submitted to an intense subdivision, that process added more than 1,500 new municipalities to its municipal mesh. Such reconfiguration of the territorydivision, on local scale, was subject matter of researches in numerous scientific areas, such as geography, social sciences, economics and law. This paper analyzes these researches, seeking to uncover the explanatory content for the phenomenon, provided by the different researchers, as well as points out advances and limitations of these explanations. Based on these advances and limitations, it seeks to construct a geographic explanation, describing the phenomenon as transcalar action, a result of the relationship between man and the geographic space.
\end{abstract}

Key words: municipality creation, emancipation of municipalities, geographical scale, territorial division.

\footnotetext{
${ }^{1}$ Professor do Departamento de Geografia e do Programa de Pós-Graduação e Pesquisa em Geografia da Universidade Federal do Paraná (UFPR). E-mail: adilar@ufpr.br.
} 


\section{LA CREACIÓN DE MUNICIPALIDADES: UNA ACCIÓN TRANSESCALAR RESULTADO DE LA RELACIÓN SOCIEDAD Y ESPACIO.}

\section{Resumen}

En las últimas dos décadas del siglo $\mathrm{XX}$, el territorio brasileño pasó por una intensa compartimentación de su territorio, el proceso añadió más de 1500 nuevas municipalidades a su malla municipal. Esa reconfiguración de la división del territorio, en escala local, fue tema de una investigación de inúmeras áreas científicas, como la geografía, las ciencias sociales, las económicas y jurídicas. El presente artículo analiza esas investigaciones, buscando desvendar el contenido explicativo para el fenómeno, fornecido por los distintos investigadores, así como se demuestra los avanzos y limitaciones de esas explicaciones. Con base en esos avanzos y limitaciones, se busca construir una explicación de cuño geográfico, cualificando el fenómeno como una acción transescalar, resultado de la relación del hombre con el espacio geográfico.

Palabras clave: Creación de municipalidad, emancipación municipal, escala geográfica, división territorial.

\section{INTRODUÇÃO}

Durante a década de 80 e 90 do século XX, o território brasileiro passou por alteração significativa no que diz respeito ao número de recortes territoriais locais, ou seja, de municípios. No ano de 1980, o Brasil possuía 3.974 municípios. Em 1996 havia 4.987 municípios, quando foi aprovada no Congresso Nacional a Emenda Constitucional n. ${ }^{\circ} 15$. Essa emenda manteve a prerrogativa dos estados para criar municípios, mas fez novas exigências, como o estudo de viabilidade municipal, além de estender o plebiscito ao conjunto do eleitorado, tanto da área que viria a formar o novo município como no de origem. Desde então, foram instalados 539 municípios criados antes da promulgação da emenda e 64 municípios no ano de 2001, criados após Emenda Constitucional. Tais emancipações fizeram com que no ano de 2016 o Brasil tenha 5.570 municípios (CIGOLINI e CACHATORI, 2012).

Para entender o surgimento dessas novas municipalidades muitas pesquisas foram realizadas. Alguns pesquisadores que se debruçaram sobre o tema podem ser destacados, como:Bremaeker (1992), Mello (1992), Noronha (1997), Shikida (1998), Cigolini (1999), Gomes e Mac Dowell (2000), Lima (2000), Ayres (2001), Cataia (2001), Caldas (2002), Motta Junior (2002), Tomio (2002), Siqueira (2003), Pinto (2003), Fávero (2004), Banfanti e Guimarães (2004), Rivera e Motta Pinto (2004), Bezerra (2006), Alves (2006) e Wanderley (2007). 
Numa primeira análise, nota-se que essas pesquisas se preocuparam mais em entender as causas e as conseqüências das emancipações, contribuindo para avançar no esclarecimento sobre o processo emancipatório. Entretanto, nota-se que, tanto os autores que pesquisaram as causas da criação de municípios, quanto àqueles que investigaram suas consequiências, apresentam resultados bastante díspares. (CIGOLINI e CACHATORI, 2012).

Em relação às causas, a criação de municípios é explicada por fatores que vão desde a extensão territorial - um atributo puramente físico-territorial -, até fatores como a descentralização, ou seja, questões políticas que resultam de certa compreensão da organização do próprio Estado, passando por questões de cunho econômico, manipulação do território, distribuição de recursos, ausência se serviços básicos, entre outras. As consequências apontam para duas direções. Por um lado, a criação de máquinas públicas e os recursos necessários para mantê-la são tidos como um aspecto negativo do fenômeno. Por outro lado, as pesquisas que se debruçaram sobre os efeitos locais, ou seja, nos lugares que sofreram processos de emancipações, constataram que tais efeitos são positivos, sob diversos aspectos (CIGOLINI, 2017).

Como o mesmo fenômeno pode ser interpretado de modos tão diferentes? Essa questãoimpõe a necessidade de entender o porquê de conclusões tão diversas. Consequentemente, o trabalho ora apresentado busca, pela análise dos trabalhos citados, pistas que possam auxiliarnessa reflexão. Percebeu-se que a escala de análise de cada trabalho foi diferenciada, pois o fenômeno pode ser visto com base numa ótica local, estadual ou nacional. Segundo Castro (2003a), a análise geográfica precisa considerar que o sentido do fenômeno é dado por seu recorte espacial. Dessa forma, uma interpretação geográfica das pesquisas referentes à criação de municípios pode ser feita a partir da escala geográfica, conceito esse que pode "[...] expressar a representação dos diferentes modos de percepção e de concepção do real." (CASTRO, 2003a, p. 118). A relação entre a escala e o objeto de pesquisa também foi levantada por Racine, Raffestin e Ruffyc (1983, p. 125) "Colocar o problema da escala é também colocar o problema da pertinência da ligação entre uma unidade de observação e o atributo que associamos a ela".

Cada autor, ao pesquisar as causas e consequências da criação de municípios, implícita ou explicitamente, privilegiou um nível escalar, de modo que as conclusões resultam da observação de ações ou do tratamento de dados locais, estaduais ou nacionais. Muitas vezes se percebe que existem, com maior ou menor peso, fatores intervenientes oriundos de outras escalas, mas o papel de cada um e a forma como se articulam para resultar no fenômeno não é objeto de pesquisa em nenhum trabalho. Destaca-se que o presente artigo é em grande parte resultado da reflexão feita quando da construção de 
tese de doutorado, destinada a estudar a compartimentação do território brasileiro em municípios numa perspectiva histórico-geográfica. (CIGOLINI, 2009).

\section{ENTRE O LOCAL E O NACIONAL: AS PERSPECTIVAS ESCALARES NAS PESQUISAS SOBRE CRIAÇÃO DE MUNICÍPIOS.}

Autores como Bremaeker (1992), Mello (1992), Noronha (1997), Shikida (1998) e Caldas (2002) viram nas características locais do território os maiores incentivos para as emancipações.Para eles, as emancipações são explicadas pelas condições demográficas, econômicas, sociais ou políticas locais.

Nesse caso, a participação dos atores das outras escalas ocorre pela criação de normas e condições políticas que criam um ambiente favorável à emancipação, ou seja, os estados federados e a União têm um papel político e normativo. Essa tese é fortalecida pelo trabalho de Caldas (2002) quando mostra que, mesmo existindo no Estado de São Paulo centenas de áreas em condições de emancipar-se, nem todas o fizeram. Se a emancipação fosse decorrente das ações dos estados ou da União, seria esperado que o fenômeno abrangesse todas as áreas em condições para emancipação. Como vimos, segundo Caldas (2002), a capacidade organizativa dos habitantes locais é um fator condicionante. Os trabalhos dos autores citados acima, que buscam explicar as emancipações com base nos atributos territoriais e na ação dos atores da escala local, também permitem concluir que as emancipações só acontecem quando existem grupos locais dispostos a buscá-las e quando os habitantes votam favoravelmente ao processo.

Outros autores, como Cigolini (1999), Lima (2002), Ayres (2001), Motta Junior (2002), Tomio (2002), Siqueira (2003), Banfanti; Guimarães e Motta Pinto (2004) e Alves (2006), deram maior peso a processos existentes na escala do Estado Federado, como explicação. Ressalta-se que os trabalhos de Tomio (2002) e Alves (2006) não procuraram exatamente explicar o porquê da criação de municípios, mas as causas da variação do número de unidades criadas nos estados, utilizando-se de dados e informações referentes a essa escala.

Os autores que priorizaram essa escala associam o fenômeno com interesses dos governos estaduais, com a legislação estadual, com dinâmicas demográficas e econômicas regionais, com a forma de interação dos poderes Executivo/Legislativo estaduais, com a busca da representatividade política ou com a dinâmica de ocupação do território.

Nesses casos, o Estado não somente cria as condições para a emancipação dos municípios, como também pode incentivá-las ou facilitá-las, como mostrou Motta Junior (2002). Outro aspecto foi mostrado por Siqueira (2003), para quem as emancipações só 
podem ser compreendidas pela análise das condições regionais do Estado de São Paulo. No trabalho, embora a situação local tenha sido utilizada para justificar as emancipações, o conjunto delas só pode ser entendido utilizando-se como referência a caracterização regional. Mas a tese de que é no Estado Federado que se encontra a explicação sobre o número de unidades emancipadas é mais claramente defendida por Tomio (2002) e Alves (2006), cujos trabalhos demonstraram que, onde havia, no âmbito do estado, um executivo com elevada força política e contrário à criação de municípios, como é o caso da Bahia (após 1988) e, em parte, de Pernambuco, as emancipações não foram permitidas ou foram cerceadas. Lima (2000) também associa a criação de municípios às dinâmicas políticas e econômicas do Estado do Espírito Santo e diz que elas somente podem ser entendidas no quadro particular de cada estado.Em todos esses trabalhos, mesmo que a emancipação tenha ocorrido utilizando-se as características locais do território como discurso motivador, ela só pode ser compreendida pela análise das características, ação dos atores e interesses existentes na escala do Estado Federado.

Um autor que pesquisou as causas da emancipação, cuja explicação só pode ser compreendida se associada à dinâmica política do Estado Nacional no período recente é Cataia (2001). Sua explicação se pautou nas características do Pacto Federativo, que permite a existência da "guerra dos lugares", sendo a dinâmica da criação de municípios concebida dentro dessa lógica, pela qual os atores hegemônicos criam mais espaços políticos, aumentando suas possibilidades de manipulação do território. No quadro geral da nação, seriam criadas normas e empreendidas ações políticas que facilitariam a ação desses atores e isso resultaria na fragmentação do território com maior intensidade. A abordagem desse autor também estabeleceu uma ligação direta entre a criação de municípios e problemas federativos: "A dinâmica das fronteiras municipais evidencia a crise do pacto federativo brasileiro. $\mathrm{O}$ aumento do número de municípios no Brasil acaba por ser funcional à ação das empresas transnacionais que podem ter a totalidade do território brasileiro como recurso.” (CATAIA, 2001, p. 218). De acordo com o raciocínio subjacente à relação exposta pelo autor, quando se aceita a tese daqueles que são contra a criação de municípios, pode-se entender que a criação de municípios reflete a crise do pacto federativo. Mas, ao contrário, para quem aceita a tese daqueles que são a favor da criação de municípios, a dinâmica dos limites locais não representa uma crise, mas uma qualidade do pacto federativo. Essa ideia de que as normas estabelecidas na escala nacional seriam responsáveis pelas emancipações pode ser fortalecida 
se observamos que, no período militar brasileiro, quando os requisitos para a emancipação foram centralizados na União e eram mais rígidos, a criação de municípios não ocorria de forma intensa.

As consequências da criação de municípios também são vistas com base em escalas diferenciadas, embora com menos diversidade, pois somente o trabalho de Gomes e Mac Dowell (2000) se diferencia. O objeto de análise desses autores é o conjunto da malha municipal e as consequências da criação do município para esse conjunto, cuja escala de análise é o território nacional. Já os outros autores, como Pinto (2003), Fávero (2004), Bezerra (2006) e Wanderley (2007), têm como característica comum estudar as consequências locais, ou seja, para as unidades emancipadas ou para os municípios-mãe. As outras escalas são utilizadas, nesse caso, como referência comparativa.

Enquanto Gomes e Mac Dowell (2000) não apresentam nenhum aspecto positivo no processo, pois a criação de municípios só teria consequências maléficas à nação, os outros autores apresentam aspectos bastante positivos, mesmo com ressalvas, como Bezerra (2006) e Wanderley (2007). Embora esse grupo não tenha pesquisado propriamente as causas da criação de municípios, todos os autores têm como ponto comum associar a causa da criação de municípios com descentralização, especialmente após a Constituição de 1988.

Como se nota, há uma abordagem escalar definida, seja para pensar as causas da criação de municípios, seja para pensar suas consequências. De acordo com Vainer (2001, p. 147), "Escolher uma escala é também, quase sempre, escolher um determinado sujeito, tanto quanto um determinado modo e campo de confrontação”. Para Castro,

A análise geográfica dos fenômenos requer objetivar os espaços na escala em que eles são percebidos. Este pode ser um enunciado ou um ponto de partida para considerar, de modo explícito ou subsumido, que o fenômeno observado, articulado a uma determinada escala, ganha um sentido particular (CASTRO, 2003a, p. 120).

Em consequência, embora seja o mesmo fenômeno, a criação de municípios e suas consequências foram percebidas e apresentadas de modo diferenciado, em parte, pela escala da abordagem. Quando se opta por observar fenômenos que perpassam diferentes ordens de escalas, dispensam-se ou negligenciam-se variáveis que atuam em outras escalas. Lacoste argumenta: 
Ao plano do conhecimento não há nível de análise privilegiado, nenhum deles é suficiente, pois o fato de se considerar tal espaço como campo de observação irá permitir apreender certos fenômenos e certas estruturas, mas vai acarretar a deformação ou a ocultação de outros fenômenos e de outras estruturas, das quais não se pode, a priori, prejulgar o papel e, portanto, não se pode negligenciar (LACOSTE, 1989, p. 81).

Esses argumentos revelam, portanto, um problema metodológico, que é a ausência de pesquisas que abordem as emancipações como uma ação transescalar. Tomio (2002), ao pesquisar o contexto institucional das emancipações após 1988, apontou, do ponto de vista das normas, a interação entre os processos das diferentes escalas, embora sua pesquisa tenha se restringido à escala dos estados federados.

Por outro lado, as pesquisas precisam ser avaliadas em função do que se propuseram a fazer e, nesse sentido, não se trata de adotar ou negar as conclusões encontradas. Cada uma, a seu modo, embora muitas vezes com limitações metodológicas, chegou aos resultados propostos. Mas, se de uma só das pesquisas apresentadas, não é possível concluir sobre a interação dos atores e processos das diferentes escalas com a criação de municípios, o conjunto delas fornece elementos que permitem reflexões nesse sentido. Recorre-se novamente a Vainer, que, ao referir-se a processos econômicos, políticos e sociais, pergunta: "Haverá ainda hoje algum processo social relevante cuja compreensão e modificação seja possível através de uma análise ou intervenção uniescalar?” (2001, p. 146).

Assim, para a criação de municípios, o papel da União tem que ser considerado, pois, mesmo admitindo-se, como Caldas (2002), que a descentralização da legislação e de recursos não seria suficiente para explicar as emancipações - ela serve como agente incentivador. Mas, como norma geral, essa ação se objetiva no território de diferentes modos. Assim, da existência de uma norma geral una para todo território, cada estado adotou requisitos específicos, em função da conjuntura política e das suas características territoriais, tornando o processo de emancipação bastante diverso.

Nos estados, ora são criadas maiores possibilidades de desmembramentos municipais, ora tais possibilidades são cerceadas pelo aumento das exigências legais, revelando o embate entre forças favoráveis e contrárias às emancipações municipais. Isso mostra que as escalas dos estados e a posição dos atores interessados também intercedem no processo. Em alguns estados, a primazia da iniciativa é do local, isto é, a solicitação formal para se iniciar o processo que pode conduzir à emancipação tem que partir da população local. Em outros, essa primazia é do Poder Legislativo, o que cria diferentes ordens de ação. Assim, é 
igualmente inegável que a escala do estado é um condicionante forte, pois produz, com base na norma geral, condições políticas específicas em cada unidade federada para que as emancipações ocorram.

No período ora em análise (década de 80 e 90 do século XX), essa articulação entre normas gerais e particulares criaram um estoque de centenas de distritos e povoados no Brasil que guardavam condições de tornarem-se municípios. Por que isso não ocorreu? Uma condição que parece importante para criar novos municípios é, além da existência de localidades aptas, a existência de grupos locais com condições políticas e disposição para buscar a emancipação, mesmo que essa disposição seja pautada em discursos com interesses subjacentes, ou em argumentos que a realidade local não corrobora. Igualmente, no âmbito de cada localidade, os eleitores precisam estar convencidos a votar favoravelmente à emancipação, de modo que os atributos e interesses locais são partes condicionantes do processo emancipatório.

Percebe-se, assim, que os municípios são criados quando há interação das três escalas de governo. Cada uma tem seu papel, embora muitas vezes em conflito, mas, como afirma Castro (2003b, p. 16), "O território deve ser, portanto, visto como continente de um sistema de interesses, na maioria das vezes conflitantes, que são os fundamentos da necessidade da política, das suas instituições e do seu poder para o controle de conflitos.” Para Moura e Ultramari, “[...] uma análise e um posicionamento mais efetivo dos processos de fragmentação e agregação contribuiriam para o próprio reforço do Estado, enquanto orquestrador de diversidades.” (1994, p. 92). Dessas considerações podese entender que municípios são criados sob múltiplos interesses e conflitos, que podem ser horizontalizados, ou seja, das diferentes posições existentes em cada escala, ou verticalizados, ou seja, dos conflitos de interesses existentes entre as escalas de governo.

Desse modo, o conjunto das pesquisas desconstrói a ideia de que é possível, com base em estudos de escalas específicas, explicar as causas e as consequências da criação de municípios no Brasil. Ao mesmo tempo, indica que o fenômeno é uma ação transescalar, resultante da interação de ações entre as escalas geográficas, que podem ocorrer de forma diferenciada segundo o estado federado ou o interesse dos atores.

Assim, alguns pressupostos já podem ser estabelecidos em relação ao processo de criação de municípios no Brasil:

- A criação de municípios é uma ação transescalar, pois ocorre quando há convergência de ações nas distintas escalas geográficas. 
- A variação na criação de municípios, nos estados, decorre da particularização das normas gerais produzidas pela União, que são adaptadas às conjunturas políticas e características de cada estado.

- A criação de municípios não é uma decorrência direta da organização federativa brasileira. Admite-se, no entanto, que a forma como a Federação está estruturada pode ser condicionante do processo.

- Os municípios são criados porque essa ação encontra respaldo político e social.

Como se anunciou na Introdução do presente trabalho, os resultados obtidos até agora ainda não são capazes de dar uma resposta satisfatória ao fenômeno ora abordado.

As pesquisas apresentadas contribuíram para entender um aspecto do fenômeno, ou casos particulares que ocorrem em diferentes lugares. Indicaram também que é possível reconhecer que o objeto pode ser investigado sob uma multiplicidade de abordagens, que refletem as perspectivas próprias de cada campo disciplinar e abarcam, igualmente, o olhar político de cada pesquisador.

Quando, no nível da Federação, se discorre sobre as consequências das emancipações, como fizeram Gomes e Mac Dowell (2000), pode-se considerar que a distribuição do FPM, entre outros repasses, para um maior número de municípios gera déficit público e é maléfica. Entretanto, visto de baixo, a partir das pequenas localidades, que enfrentam no seu dia a dia um grande número de dificuldades básicas, com pouco acesso a serviços estatais, esses mesmos recursos podem ser considerados investimentos que geram inúmeros benefícios.

\section{CONSIDERAÇÕES FINAIS}

A criação de municípios, para uns, é decorrente da busca do espaço político ou do interesse particular de grupos hegemônicos ou das elites, mesmo que locais. Para outros, é a oportunidade do desenvolvimento, da redistribuição da renda pública ou decorre simplesmente da elevada extensão territorial e da falta de serviços públicos. Existem ainda aqueles que enxergam na emancipação a possibilidade do exercício da democracia e da cidadania. Muitos indicam que o desenvolvimento econômico leva à emancipação, mas, ao contrário, alguns autores afirmam que é a falta de desenvolvimento econômico que leva o fenômeno a ocorrer. Como disse Noronha (1997), talvez não seja possível separar apenas um fator, mas um conjunto deles. Desse modo, concorda-se com Lima (2000) quando diz que não se pode entender a questão municipal sem considerar o território em sua materialidade, assim como a história dos lugares. Mas, por outro lado, um estudo que explique as emancipações 
teria que ser baseado na história particular de cada unidade, sendo, portanto, inviável uma explicação geral? O que uniria o fenômeno?

Concorda-se que a existência de um território político demanda estratégias diversas, sejam essas estratégias locais ou oriundas de outras escalas. Concorda-se que a criação de municípios ocorre em lugares com características bastante diferenciadas, sob as mais diversas justificativas. Entretanto todas as motivações deixam transparecer que a criação dessas unidades não tem um fim em si próprio, mas sãoum meio pelo qual os atores procuram criar oportunidades, já que o espaço, quando apropriado como um território, transforma-se num trampolim que permite, aos grupos, acesso a novas relações institucionais, abrindo um leque de possibilidades.

Desse modo, a criação de municípios não é algo que possa ser explicado por razões conjunturais específicas de um dado período ou de um lugar particular. Cigolini (2012)mostra que a criação de municípios no período colonial brasileiro ocorria, por um lado, em virtude da organização da vida local,mas, por outro lado, por ações geopolíticas inseridas num objetivomaior: a estratégica de ocupação e de proteção do território brasileiro. Cigolini também mostra (2015;2016) que, posteriormente, durante Império, o municípiofoi usado uma força centrípeta, garantindo a integridade do poder político e, mesmo como entidade administrativa, sua criação continuou em todo território nacional. Na República, mesmo em momentos políticos distintos, de exceção política, centralização ou descentralização, igualmente houve a criação de municípios, cujos momentos de maior ocorrência foram de 1946 a 1964 e nas décadas de 80 e 90 do século XX.

Desse modo concorda-se com Gottman (1973), quando argumenta que a divisão territorial é um elemento central do estabelecimento da vida comunitária, essencial à organização política, que estrutura e organiza os grupos, e permite o reconhecimento da existência política daquela comunidade. Em outra palavras, o espaço seria dividido porque o reconhecimento de uma comunidade política decorre do reconhecimento da jurisdição dessa comunidade sobre uma porção do espaço.

Desse modo pode-se sugerir, que a resposta à questão do por que municípios são criados, estariamais ligada a divisão do território como um fenômeno estrutural, inscrevendose se nas formas e no conteúdo da vida social, do que em aspectos funcionais determinados por ações e interesses específicos, como mostra boa parte da literatura sobre o tema. 


\section{REFERÊNCIAS BIBLIOGRÁFICAS}

ALVES, A. C. O contexto institucional e a relação entre Executivo e Legislativo na criação de municípios no Paraná, 1988-1996. (Dissertação - Mestrado em Sociologia). Universidade Federal do Paraná, Curitiba, 2006.

AYRES, É. O. J. Processo e política atual de desmembramento municipal no Maranhão. (Tese Doutorado em Estruturas Ambientais Urbanas). Faculdade de Arquitetura e Urbanismo, Universidade de São Paulo, São Paulo, 2001.

BANFANTI, G.; GUIMARÃES, R. V. O processo de criação de novos municípios no Mato Grosso. Anais do II Encontro de Geografia do Mato Grosso. Universidade Federal do Mato Grosso, Cuiabá, 2004.

BEZERRA, J. da S. O território como um trunfo: um estudo sobre a criação de municípios na Paraíba (anos 90). (Dissertação - Mestrado em Geografia). Universidade Federal da Paraíba, João Pessoa, 2006.

BREMAEKER, F. E. J. Os novos municípios: surgimento, problemas e soluções. Série Estudos Especiais n. 04, IBAM, Rio de Janeiro, 1992.

CALDAS, E. L. O processo de criação de municípios no Estado de São Paulo entre 1991 e 1996: uma abordagem institucionalista. (Dissertação - Mestrado em Ciência Política). Fundação Getúlio Vargas, São Paulo, 2002.

CASTRO. O problema da escala. In: CASTRO, I. E. de; COSTA, P. C. da; CORRÊA, R. L. (Orgs). Geografia: conceitos e temas. 5. ed. Rio de Janeiro: Bertrand Brasil, 2003a.

CASTRO. Instituições e território: possibilidades e limites ao exercício da cidadania.Geosul. V.18, n. ${ }^{\circ}$ 36, jul./dez. - Florianópolis: Editora da UFSC, 2003 b.

CATAIA, M. A. Território nacional e fronteiras internas: a fragmentação do territóriobrasileiro. (Tese - Doutorado em Geografia). Universidade de São Paulo, São Paulo, 2001.

CIGOLINI, A. A. Análise da literatura explicativa sobre o processo contemporâneo da criação de municípios no Brasil. REB - Revista de Estudios brasileños, volume 4, número 06. Universidade de Salamanca/Universidade de São Paulo, 2017. Disponível em:

https://reb.universia.net/article/view/2553/analisis-literatura-explicativa-proceso-contemporaneocreacion-municipios-brasil.

CIGOLINI, A. A. Ocupação do território e a criação de municípios no período Imperial brasileiro. Revista Mercator, Fortaleza, v. 14, n. 1, p.7-19, jan./abr. 2015.

CIGOLINI, A. A. Ocupação do território e a criação de municípios no período Republicano brasileiro. Revista bibliográfica de geografiay ciências Sociales. Universidad de Barcelona, Vol. XIX, $\mathrm{n}^{\circ}$ 1101, 2014.

CIGOLINI. A. A. e CACHATORI, T. Análise do processo de criação de municípios no Brasil. Atas do XII Colóquio Internacional de Geocrítica. Bogotá: Colômbia, 2012. Disponível em: http://www.ub.edu/geocrit/coloquio2012/actas/11-A-Cigolini.pdf. 
CIGOLINI, A. A. Ocupação do território e a geopolítica da criação de municípios no período colonial brasileiro. Boletin Gaúcho de Geografia, n. ${ }^{\circ}$ 38, Associação Brasileira de Geógrafos, Seção Porto Alegre, Porto Alegre, RS, Brasil, 2012.

CIGOLINI, A. A. Território e criação de municípios no Brasil: Uma abordagem históricogeográfica sobre a compartimentação do espaço. (Tese - Doutorado em Geografia). Universidade Federal de Santa Catarina, Florianópolis, 2009.

CIGOLINI, A. A. A fragmentação do território em unidades político-administrativas: análise da criação de municípios no Estado do Paraná. (Dissertação - Mestrado em Geografia). Universidade Federal de Santa Catarina, Florianópolis, 1999.

FÁVERO, E. Desmembramento territorial: o processo de criação de municípios avaliação a partir de indicadores econômicos e sociais. (Tese - Doutorado em Engenharia Urbana). Departamento de Engenharia de Construção Civil. Escola Politécnica da Universidade de São Paulo, 2004.

GOTTMANN, J. The significance of territory.The University Press of Virginia, 1973.

GOMES, G. M.; MAC DOWELL, M. C. Descentralização política, federalismo fiscal e criação de municípios: o que é mau para o econômico nem sempre é bom para o social. Texto para discussão n. ${ }^{\mathbf{0}}$ 706, IPEA, Brasília, 2000.

LACOSTE, Y. A geografia: isso serve, em primeiro lugar, para fazer a guerra. $2^{\text {a }}$..ed.Campinas: Papirus, 1989.

LIMA, M. H. P. O processo de emancipação municipal no Estado do Espírito Santo. (Dissertação - (Mestrado em Geografia). Instituto de Geociências. Universidade Federal do Rio de Janeiro, Rio de Janeiro, 2000.

MELLO, D. L. de. A multiplicação de municípios no Brasil. Revista de Administração Municipal, v. 39. n. ${ }^{\circ}$ 203, p. 23-28, IBAM, Rio de Janeiro, 1992.

MOURA, R.; ULTRAMARI, C. Territorialidades em movimento. Metrópole, grande Curitiba: teoria e prática. Curitiba: IPARDES, 1994.

MOTTA JUNIOR, V. da.A criação de pequenos municípios como um fenômeno da descentralização política: o caso de Itaoca-SP. (Dissertação - Mestrado em Ciências Sociais). Centro de Educação e Ciências Humanas. Universidade Federal de São Carlos, São Paulo, 2002.

NORONHA, R. Emancipação municipal: implicações espaciais da divisão políticoadministrativa do território fluminense. (Dissertação - Mestrado em Geografia). Instituto de Geociências, Universidade Federal do Rio de Janeiro. Rio de Janeiro, 1997.

PINTO, G. J. Do sonho à realidade: Córrego Fundo-MG: fragmentação territorial e criação de municípios de pequeno porte. (Dissertação - Mestrado em Geografia). Instituto de Geociências. Universidade Federal de Uberlândia. Minas Gerais, 2003.

RACINE J.;RAFFESTIN, C. e RUFFY, V. Escala e ação, contribuições para a interpretação do mecanismo de escala na prática da Geografia. Revista Brasileira de Geografia, n. 01 jan./mar., IBGE: Rio de Janeiro, 1983. 
RIVERA, M. S. P.; MOTTA PINTO, G. F. P. Mato Grosso: conformação territorial.Anais do II Encontro de Geografia do Mato Grosso. Universidade Federal do Mato Grosso,Cuiabá, 2004.

SHIKIDA, C. D. A economia política da emancipação de municípios em Minas Gerais. ESAF, Brasília, 1998.

SIQUEIRA, C. G. Emancipação municipal pós Constituição de 1988: um estudo sobre o processo de criação dos novos municípios paulistas. ( Dissertação - Mestrado em Ciência Política). Departamento de Ciência Política. Instituto de Filosofia e Ciências Humanas. Universidade Estadual de Campinas. São Paulo, 2003.

TOMIO, R. de L. C. Instituições, processo decisório e relações Executivo-Legislativo nos Estados: estudo comparativo sobre o processo de criação de municípios após a

Constituição de 1988. (Tese - Doutorado em Ciências Sociais). Departamento de Ciência Política. Instituto de Filosofia e Ciências Humanas. Universidade Estadual de Campinas. São Paulo, 2002.

VAINER, C. B. As escalas do poder e o poder das escalas: o que pode o poder local? Anais - Volume I - IX Encontro Nacional da ANPUR: Rio de Janeiro, 2001.

WANDERLEY, C. B. Emancipações municipais em Minas Gerais: estimativas e seus impactos sociais. Fundação Getúlio Vargas, Rio de Janeiro, 2007.

Recebido em Abril de 2017

Aprovado em Junho de 2017

Publicado em Agosto de 2017 